\title{
Male reproductive traits of full-sibs of different age classes in three-spined sticklebacks (Gasterosteus aculeatus)
}

\author{
Marion Mehlis ${ }^{*}$ and Theo CM Bakker
}

\begin{abstract}
The process of ageing is associated with negative effects of mutations acting late in life, which range from those affecting cells to those affecting the whole organism. In many animal taxa, the deterioration of the phenotype with age also affects traits such as males' primary and secondary sexual characteristics. In three-spined sticklebacks (Gasterosteus aculeatus), males usually reproduce at one or two years of age. To see whether sexual selection has the potential to differ between young and old males, full-sib brothers of different age classes were compared, which were bred and raised under standardised laboratory conditions. During two simulated, successive breeding seasons males were allowed to build their nest in single tanks either in the first ("young males") or in the second ("old males") breeding season. A comparison of reproductively active brothers of the first and second breeding season showed that older males produce more but smaller sperm, which might be of lower quality. The fact that older males stored more sperm is size dependent as the results show that larger males possess a greater absolute testis mass, which is inextricably linked to sperm number. However, independent of body size, old males had a lower intensity of red/orange and UV breeding coloration as well as a reduced testis melanisation, which might have consequences in female mate choice and sperm competition.
\end{abstract}

Keywords: Ageing, Sperm competition, Sexual selection, Oxidative stress, Carotenoids, Testicular melanisation

\section{Background}

More than 300 different theories on the proximate and ultimate causes of ageing (Medvedev 1990) have been proposed over the past six decades (for reviews see Hughes and Reynolds 2005; Rose et al. 2008; Milewski 2010; Johnson and Gemmel 2012). Ultimate causes investigate the tension between longevity and reproduction. For example, Medawar ("mutation accumulation theory": Medawar 1952) postulates that due to natural selection (e.g. predation) individuals within a population do not live long enough to accumulate deleterious mutations that would reduce fitness late in life. Furthermore, Williams ("antagonistic pleiotropy": Williams 1957) reveals that some genes, which are responsible for an increased reproductive investment when being young, contribute to a lower rate of investment in maintenance and reproduction later in life. Researchers interested in proximate causes

\footnotetext{
* Correspondence: mmehlis@evolution.uni-bonn.de

Institute for Evolutionary Biology and Ecology, University of Bonn, An der Immenburg 1, D-53121, Bonn, Germany
}

focus on mechanisms such as the accumulation of damage to cells and cell function over time caused by free radicals produced during cellular metabolism ("oxidative stress": Harman 1956). To date there is no universal theory of ageing, possibly because the process itself is multicausal (see Holliday 2006).

Theoretical considerations aside, there has recently been considerable interest in the effects of ageing on sexually selected traits. For example, two indicators of male sexual attractiveness, tail length in barn swallows (Hirundo rustica) (Balbontín et al. 2011) and foot colour in bluefooted boobies (Sula nebouxii) (Velando et al. 2011) were shown to decrease with age. In many animal taxa, ageing has effects on reproductive success, which may be negative (e.g. Dean et al. 2010) as well as positive (e.g. DuVal 2012). In some cases, males of intermediate age were most successful (e.g. Raveh et al. 2010). Also in humans (Homo sapiens), testicular volume was significantly different among age classes, with men between $30-60$ years showing the greatest testicular volume (Yang et al. 2011). If old 
males are of lower quality, females will discriminate against them (Beck and Promislow 2007). This exactly happened in the house mouse (Mus musculus domesticus); old males and their scent were less attractive to females (Garratt et al. 2011). Similarly, in the field cricket (Gryllus bimaculatus), females had a strong preference for the songs of young males (Verburgt et al. 2011). On the other hand, in Drosophila bipectinata females preferred to mate with older males, presumably due to the fact that old males mated faster, copulated longer and inseminated more (Somashekar and Krishna 2011). In guppies (Poecilia reticulata) old males produced longer but slower sperm and they had larger reserves of strippable sperm when compared to young males (Gasparini et al. 2010). However, artificial insemination did not reveal any effect of age on sperm competition success (Gasparini et al. 2010). Overall, a number of studies investigated the influence of ageing on reproductive traits resulting in contradictory findings, which might partly be explained by the different breeding systems of the study animals (see Johnson and Gemmel 2012 for an overview).

The three-spined stickleback (Gasterosteus aculeatus) is a good model system to study the influences of male age on reproductive traits for several reasons. Depending upon location, sticklebacks breed from April to August. Individuals normally reach reproductive age in their second (one-year-old) or third summer (two-year-old) and die after one or two breeding seasons (but see Gambling and Reimchen 2012 for a report of some populations in which individuals live for six years or more). During the breeding season males establish territories in the shallow shore region and build a nest composed of filamentous algae. Furthermore, males usually develop a conspicuous red/orange coloration in the cheek region, court many females and provide all of the parental care (Wootton 1976). The intensity of male breeding coloration is one of the key determinants of female mate-choice decisions (e.g. McLennan and McPhail 1990; Bakker and Milinski 1993). Once a female has made her choice, she pushes her way into the male's nest, deposits her eggs and then leaves as the territorial male enters the nest behind her to fertilise the clutch. Female choice can be circumvented to an extent by sneaking behaviour, in which an intruding male dashes through the nest to deposit sperm immediately before or after the territory holder. This is a common behavioural tactic of territorial males in many populations (e.g. Largiadèr et al. 2001), indicating that sperm competition is an important part of the stickleback breeding system. A recent study revealed that competitive males, which had succeeded in establishing a territory and attracting ripe females, performed most of the sneak attempts (Candolin and Vlieger 2013).

In the three-spined stickleback spermatogenesis only occurs during the short photoperiods preceding the breeding season (Borg 1982), resulting in a larger number of sperm stored in testes of virgin males (e.g. early spring) compared to those of multiply mated males (e.g. late summer) (Zbinden et al. 2001). As stickleback males are sperm limited over the course of one breeding season, careful sperm allocation is a critical fitness component (Zbinden et al. 2003, 2004). Overall then, both the intensity of males' breeding coloration (Bakker and Milinski 1993) and gonadal investment (Cubillos and Guderley 2000) have a positive influence on reproductive success. Hence, on the basis of stickleback males' breeding behaviour and the different theories of ageing it was investigated whether age has a negative influence on sexually selected reproductive traits (breeding coloration, testis and sperm traits) by using full-sib brothers of different age classes.

\section{Results}

\section{Statistical analyses}

The R 2.9.1 statistical package was used for analyses. All given p-values are based on two-tailed tests. For analyses different linear mixed effect models ("lme") were constructed using males' reproductive traits (breeding coloration, testis and sperm traits) as dependent variables and male age (young or old) as explanatory variable (Table 1). Furthermore, young and old males originated from the same family (see Methods) implying that they are not independent from each other on a genetic basis. Thus, in all models family identity was included as random factor and never removed to control for possible ancestral influences. Tests of significance were based on likelihood-ratio tests ("LRT"). The use of "lme" requires that the dependent variable is normally distributed. To achieve normal distributions of the residuals of the best explaining models according to Kolmogorov-Smirnov tests, some data were logarithmically transformed (body mass, absolute and relative testis mass, sperm number, total brightness (dorsal region) and sperm tail length), square-root transformed (relative red area of the breeding coloration in the cheek region), exponentially transformed (red/orange hue, testis melanisation $\left(\mathrm{L}^{*}\right.$ total $)$ ) or reciprocally transformed (total brightness (cheek region)). For a detailed description of all measured reproductive traits see Methods.

\section{Body traits}

Young $\left(\mathrm{N}_{\text {young }}=60\right)$ and old males $\left(\mathrm{N}_{\text {old }}=101\right)$ differed significantly in body size ("lme", $\mathrm{X}^{2}=47.842, \mathrm{P}<0.001$ ) and mass ("Ime", $x^{2}=39.942, P<0.001$ ), showing that older males were on average larger and heavier than younger ones (Table 2). Hence, whether age or size affected the observed results (see below) is hard to distinguish due to the fact that age and body size are not statistically independent from each other. Accordingly, one has to mention that body size of the used individuals was determined by age as fish grow throughout their life time. It should be valid to use the base of differences (age) in the statistical 
Table 1 Listing of all conducted linear mixed effect models "Ime"

\begin{tabular}{|c|c|c|c|c|c|c|c|c|}
\hline \multirow{2}{*}{ Dependent variables } & \multicolumn{2}{|c|}{ Explanatory variable male age } & \multicolumn{2}{|c|}{ Explanatory variable body size } & \multirow{2}{*}{$\begin{array}{l}\text { AIC male } \\
\text { age }\end{array}$} & \multirow{2}{*}{$\begin{array}{l}\text { AIC body } \\
\text { size }\end{array}$} & \multicolumn{2}{|c|}{ Sample size $(\mathrm{N})$} \\
\hline & $x^{2}$ & p-value & $x^{2}$ & p-value & & & Young & Old \\
\hline Body size $[\mathrm{cm}]$ & 47.842 & $<0.001$ & 1 & / & 61.707 & l & 60 & 101 \\
\hline Body mass [g] & 39.942 & $<0.001$ & / & / & -90.424 & / & 60 & 101 \\
\hline Body condition & 0.448 & 0.503 & / & / & -315.952 & / & 60 & 101 \\
\hline Red area [\%] & 0.192 & 0.662 & 5.245 & 0.022 & 607.296 & 602.243 & 59 & 101 \\
\hline Carotenoid chroma (A) & 5.312 & 0.021 & 4.447 & 0.035 & -59.083 & -58.218 & 59 & 99 \\
\hline UV chroma (A) & 11.091 & $<0.001$ & 0.855 & 0.355 & -538.148 & -527.912 & 59 & 99 \\
\hline Red/orange hue (A) [nm] & 3.985 & 0.046 & 1.269 & 0.260 & 43316.630 & 43319.350 & 59 & 99 \\
\hline Total brightness (A) & 8.210 & 0.004 & 6.903 & 0.009 & -1240.811 & -1239.504 & 59 & 99 \\
\hline Total brightness (R) & 16.374 & $<0.001$ & 1.595 & 0.207 & 262.555 & 277.334 & 59 & 101 \\
\hline Absolute testis mass [g] & 54.517 & $<0.001$ & 76.359 & $<0.001$ & -452.293 & -474.135 & 60 & 96 \\
\hline Relative testis mass (GSI) & 20.887 & $<0.001$ & 3.304 & 0.069 & 45.989 & 63.572 & 60 & 96 \\
\hline Testis melanisation $\left(L^{*}{ }^{*}{ }^{\prime}\right)$ & 64.591 & $<0.001$ & 19.391 & $<0.001$ & 1955.718 & 2008.869 & 60 & 96 \\
\hline Sperm number & 4.256 & 0.039 & 11.441 & $<0.001$ & 223.120 & 207.984 & 59 & 99 \\
\hline Head length $[\mu \mathrm{m}]$ & 73.952 & $<0.001$ & 15.977 & $<0.001$ & -277.861 & -219.886 & 60 & 22 \\
\hline Tail length $[\mu \mathrm{m}]$ & 11.816 & $<0.001$ & 6.773 & 0.009 & -163.597 & -158.555 & 60 & 22 \\
\hline Head width $[\mu \mathrm{m}]$ & 53.729 & $<0.001$ & 9.646 & 0.002 & -303.683 & -259.599 & 60 & 22 \\
\hline Mid-piece width $[\mu \mathrm{m}]$ & 4.268 & 0.039 & 0.676 & 0.411 & -271.444 & -267.852 & 60 & 22 \\
\hline Mid-piece volume $\left[\mu^{3}\right]$ & 9.003 & 0.003 & 3.934 & 0.047 & -298.985 & -293.916 & 60 & 22 \\
\hline Mid-piece length $[\mu \mathrm{m}]$ & 2.537 & 0.111 & 2.369 & 0.124 & -225.356 & -225.187 & 60 & 22 \\
\hline Head to tail length ratio & 0.052 & 0.819 & 0.036 & 0.849 & -540.046 & -540.030 & 60 & 22 \\
\hline
\end{tabular}

(A) colour measurements were made directly below the eye (breeding coloration).

(R) measurements were taken at the dorsum below the first dorsal spine.

(GSI) gonadosomatic index after de Vlaming et al. (1982).

$\left(\mathrm{L}^{*}\right.$ total $)$ testis brightness (see Mehlis et al. 2012 for details).

In all models family identity was included as random factor and never removed to control for possible ancestral influences. The model with the lowest AIC

(Akaike's information criterion) value represents the best approximating model.

analyses in order to find differences in reproductive traits and discuss them in an evolutionary context. Nevertheless, all models (Table 1) were run again but instead of using male age body size was included as explanatory variable. The results of these models are also listed in Table 1 . Akaike's information criterion (AIC) was used for model comparison (male age or body size as explanatory variable); the model with the lowest AIC value represents the best approximating model (Symonds and Moussalli 2011). The results showed that, apart from the relative red area of males' breeding coloration, absolute testis mass and sperm number, male age is more appropriate in explaining the observed results than body size (Table 1). Thus, only the statistically relevant results concerning male body size are described in detail and discussed later on. Moreover, young and old males did not differ significantly in physical conditions ("lme", $x^{2}=0.448, P=0.503$ ), indicating that they had the same pre-condition during life time (Table 2).

\section{Breeding coloration}

The relative area of red breeding coloration in the cheek region did not differ significantly between young and old males $\left(\mathrm{N}_{\text {young }}=59, \mathrm{~N}_{\text {old }}=101 ;\right.$ "lme", $\mathrm{x}^{2}=0.192$, $\mathrm{P}=0.662$; Table 2 ) but it was significantly explained by body size ("Ime", $\mathrm{X}^{2}=5.245, \mathrm{P}=0.022$ ), with larger males showing a significantly greater relative area of the red breeding coloration. However, young and old males differed significantly in carotenoid chroma $\left(\mathrm{N}_{\text {young }}=59\right.$, $\mathrm{N}_{\text {old }}=99$; "lme", $\mathrm{X}^{2}=5.312, \mathrm{P}=0.021$ ) as well as in UV chroma $\left(\mathrm{N}_{\text {young }}=59, \mathrm{~N}_{\text {old }}=99 ;\right.$; $l m e ", \chi^{2}=11.091$, $\mathrm{P}<0.001$ ), with larger chroma values for young males in both cases (Figure 1; Table 2). Thus, young males had a significantly more saturated coloration in the red/orange spectral region. In addition, the red/orange hue was significantly lower in old males $\left(\mathrm{N}_{\text {young }}=59\right.$, $\mathrm{N}_{\text {old }}=99$; "lme", $x^{2}=3.985, \mathrm{P}=0.046$ ), indicating a more red-shifted hue of the breeding coloration in young males compared to old males (Figure 1; Table 2). Moreover, younger males showed a significantly lower total brightness in the cheek region $\left(\mathrm{N}_{\text {young }}=59\right.$, $\mathrm{N}_{\text {old }}=99$; "lme", $\chi^{2}=8.210, \mathrm{P}=0.004$; Table 2) and a significantly higher total brightness in the dorsal region $\left(\mathrm{N}_{\text {young }}=59, \mathrm{~N}_{\text {old }}=101 ;\right.$ "lme", $\mathrm{X}^{2}=16.374, \mathrm{P}<0.001$; Figure 1; Table 2). 
Table 2 Descriptive statistics (median, first and third quartile) of body traits, breeding coloration variables and testis and sperm traits of young and old males used in the analyses

\begin{tabular}{|c|c|c|c|c|c|c|}
\hline & & Young & & & Old & \\
\hline & Median & 1. Quartile & 3. Quartile & Median & 1. Quartile & 3. Quartile \\
\hline Body size $[\mathrm{cm}]$ & 4.90 & 4.70 & 5.10 & 5.20 & 4.95 & 5.40 \\
\hline Body mass [g] & 1.562 & 1.372 & 1.712 & 1.812 & 1.617 & 2.031 \\
\hline Body condition & 1.30 & 1.25 & 1.36 & 1.29 & 1.24 & 1.35 \\
\hline Red area [\%] & 14.84 & 6.22 & 27.21 & 13.74 & 6.29 & 21.94 \\
\hline Carotenoid chroma (A) & 0.450 & 0.287 & 0.538 & 0.392 & 0.189 & 0.501 \\
\hline UV chroma (A) & 0.271 & 0.244 & 0.291 & 0.245 & 0.209 & 0.273 \\
\hline Red/orange hue (A) [nm] & 506.0 & 502.0 & 509.5 & 505.0 & 501.0 & 508.5 \\
\hline Total brightness (A) & 2701.70 & 2072.17 & 3719.65 & 3267.38 & 2489.20 & 4939.09 \\
\hline Total brightness (R) & 3075.86 & 2374.82 & 4326.12 & 1963.18 & 1402.66 & 3114.35 \\
\hline Absolute testis mass [g] & 0.0107 & 0.0084 & 0.0140 & 0.0165 & 0.0135 & 0.0202 \\
\hline Relative testis mass (GSI) & 0.697 & 0.585 & 0.862 & 0.951 & 0.731 & 1.103 \\
\hline Testis melanisation $\left(L^{*}{ }_{\text {total }}\right)$ & 39.00 & 26.88 & 47.13 & 60.50 & 49.38 & 67.50 \\
\hline Sperm number & $9.3 * 10^{6}$ & $6.0 * 10^{6}$ & $12.2 * 10^{6}$ & $10.7 * 10^{6}$ & $7.9 * 10^{6}$ & $14.4 * 10^{6}$ \\
\hline Head length $[\mu \mathrm{m}]$ & 1.106 & 1.067 & 1.128 & 0.991 & 0.958 & 1.011 \\
\hline Tail length $[\mu \mathrm{m}]$ & 18.033 & 16.946 & 19.280 & 17.017 & 16.036 & 17.600 \\
\hline Head width $[\mu \mathrm{m}]$ & 1.076 & 1.048 & 1.104 & 0.999 & 0.979 & 1.018 \\
\hline Mid-piece width $[\mu \mathrm{m}]$ & 0.782 & 0.761 & 0.813 & 0.766 & 0.731 & 0.792 \\
\hline Mid-piece volume $\left[\mu m^{3}\right]$ & 0.284 & 0.268 & 0.311 & 0.256 & 0.239 & 0.281 \\
\hline Mid-piece length $[\mu \mathrm{m}]$ & 0.587 & 0.548 & 0.614 & 0.583 & 0.515 & 0.621 \\
\hline Head to tail length ratio & 0.094 & 0.089 & 0.099 & 0.091 & 0.087 & 0.098 \\
\hline
\end{tabular}

(A) colour measurements were made directly below the eye (breeding coloration)

(R) measurements were taken at the dorsum below the first dorsal spine.

(GSI) gonadosomatic index after de Vlaming et al. (1982).

$\left(L^{*}{ }_{\text {total }}\right)$ testis brightness (see Mehlis et al. 2012 for details).

\section{Testis traits}

Young $\left(\mathrm{N}_{\text {young }}=60\right)$ and old males $\left(\mathrm{N}_{\text {old }}=96\right)$ differed significantly in absolute ("lme", $\mathrm{X}^{2}=54.517, \mathrm{P}<0.001$ ) and relative testis mass ("lme", $X^{2}=20.887, P<0.001$ ) as well as in total testis brightness ("lme", $\chi^{2}=64.591, \mathrm{P}<0.001$ ), which is a measure of testicular melanisation (see Mehlis et al. 2012). While absolute and relative testis mass were both significantly higher in older males, the results show that testis melanisation was significantly lower in young males meaning that the testes of old males were less pigmented (Figure 2a-b; Table 2). However, it has to be mentioned that differences in absolute testis mass were better explained by differences in body size (lower AIC) than by male age alone, with larger males having significantly heavier testes ("lme", $\left.\mathrm{X}^{2}=76.359, \mathrm{P}<0.001\right)$.

\section{Sperm traits}

Stored sperm number differed significantly between young and old males $\left(\mathrm{N}_{\text {young }}=59, \mathrm{~N}_{\text {old }}=99\right.$; "lme", $\mathrm{x}^{2}=$ 4.256, $\mathrm{P}=0.039$ ), with older males having significantly more sperm (Table 2). However, the statistical analysis revealed that sperm number was explained in a more appropriate way by male body size (lower AIC) than by male age, with larger males having significantly more sperm ("lme", $\left.x^{2}=11.441, \mathrm{P}<0.001\right)$. Young $\left(\mathrm{N}_{\text {young }}=\right.$ $60)$ and old males $\left(\mathrm{N}_{\text {old }}=22\right)$ differed significantly in sperm morphology traits (see Figure 2c), such as head length ("lme", $x^{2}=73.952, \mathrm{P}<0.001$ ), tail length ("lme", $X^{2}=11.816, P<0.001$ ), head width ("lme", $X^{2}=53.729$, $\mathrm{P}<0.001$ ), mid-piece width ("lme", $X^{2}=4.268, \mathrm{P}=0.039$ ) and mid-piece volume ("lme", $\chi^{2}=9.003, P=0.003$ ), with young males showing higher values in all of these measures (Table 2). However, sperm of young and old males did not differ significantly in mid-piece length ("lme", $X^{2}=2.537, \mathrm{P}=0.111$; Table 2) and head to tail length ratio ("lme", $\chi^{2}=0.052, \mathrm{P}=0.819$; Table 2).

\section{Discussion}

By comparing reproductive traits of lab-reared full-sib brothers of different ages in their first reproductive season (i.e. first nest building), the present study revealed that an advanced age can have considerable consequences on the expression of reproductive traits in 


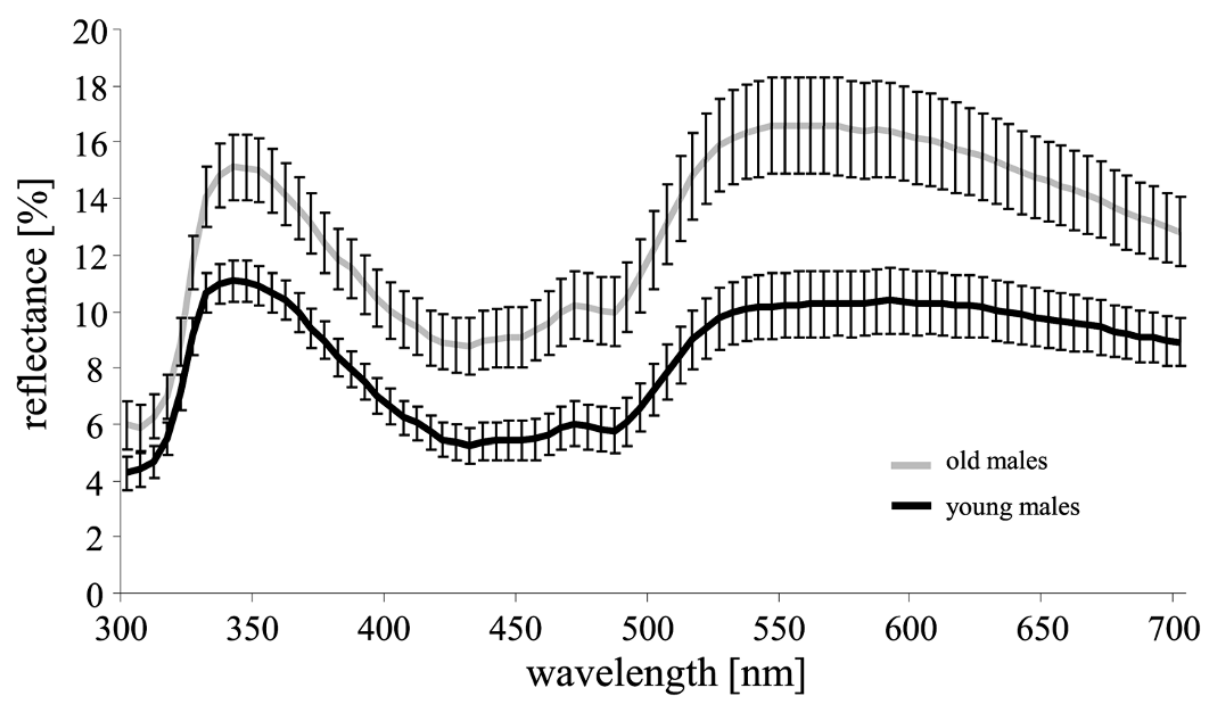

Figure 1 Representative reflectance spectrum of the carotenoid-based breeding coloration of three-spined stickleback males. Mean reflectance \pm standard error (\%) between 300 and $700 \mathrm{~nm}$ of the red/orange breeding coloration in the cheek region of reproductively active young (black line) and old (grey line) males. Reflectance was measured relative to a 98\% Spectralon white standard.

three-spined sticklebacks, which might have an influence in inter- as well as intra-sexual contexts.

In three-spined sticklebacks sperm competition occurs in many populations (e.g. Goldschmidt et al. 1992; Jamieson and Colgan 1992; Rico et al. 1992; Largiadèr et al. 2001; Vlieger and Candolin 2009). Furthermore, it is generally accepted that sperm competition is a widespread and powerful selective force affecting sperm quantity and/or sperm quality in such a way to maximise competitive fertilisation success (e.g. Rowe and PruettJones 2011). In a situation in which the risk of sperm competition is high, males should have larger testes and/ or a higher number of sperm per ejaculation (Harcourt et al. 1981; Stockley et al. 1997) assuming that fertilisation success follows a raffle-principle, so that males with more sperm will have an advantage (see Parker 1990). In the American horseshoe crab (Limulus polyphemus) young males ejaculated more total sperm and had a significantly higher sperm concentration than old males (Sasson et al. 2012). In contrast, in the guppy (Poecilia reticulata) and in zebrafish (Danio rerio), the number of extractable sperm was higher in old males (Gasparini et al. 2010; Kanuga et al. 2011). In the zebrafish study the authors argued that this might be a consequence of fewer successful breeding attempts of old zebrafish males. In three-spined sticklebacks, the number of stored sperm is significantly positively correlated with testis mass (Zbinden et al. 2001), and gonad mass is related to reproductive success (Cubillos and Guderley 2000) as is body size (Kraak et al. 1999), showing the adaptive importance of these variables. In the present study, larger (older) stickleback males also had significantly more stored sperm as well as a higher absolute testis mass.
It is hard to distinguish whether size or age affected the observed results, due to the fact that age and body size are not statistically independent from each other and especially in fish they are inextricably linked. However, all stickleback males used here were virgin as they had no opportunity to release sperm during their entire life span under laboratory conditions. In the rainbow trout (Oncorhynchus mykiss) it is known that unused sperm are reabsorbed during the post-spawning period, just before the next cycle of spermatogenesis begins (Billard and Takashima 1983), which could also be assumed for sticklebacks as in this species sperm production undergoes an annual cycle (Borg 1982). Furthermore, in a previous study it was stated that at the end of the breeding season sticklebacks testes were drastically reorganised (Schneider 1969), which is supported by the fact that testis mass declines after the breeding season (e.g. Hoffmann et al. 2012). Hence, it is likely that the sperm, which were found in the two-year-old males, were solely produced during the second winter period, leading to the interpretation that larger old males produced both absolutely and relatively more sperm.

If a male produces more gametes, these sperm will be proportionally smaller, assuming that a fixed "resource budget" is available (Parker 1982) and in the present study sperm dimensions were indeed larger in young males. Sperm morphology traits, such as sperm size, are known to be good proxies of reproductive performance in several animal species (Gomendio and Roldan 1991). For example, some studies have shown that sperm swimming ability was positively correlated with either head length, tail length or the sum of both (Pitcher et al. 2007; Gomendio and Roldan 2008; Fitzpatrick et al. 


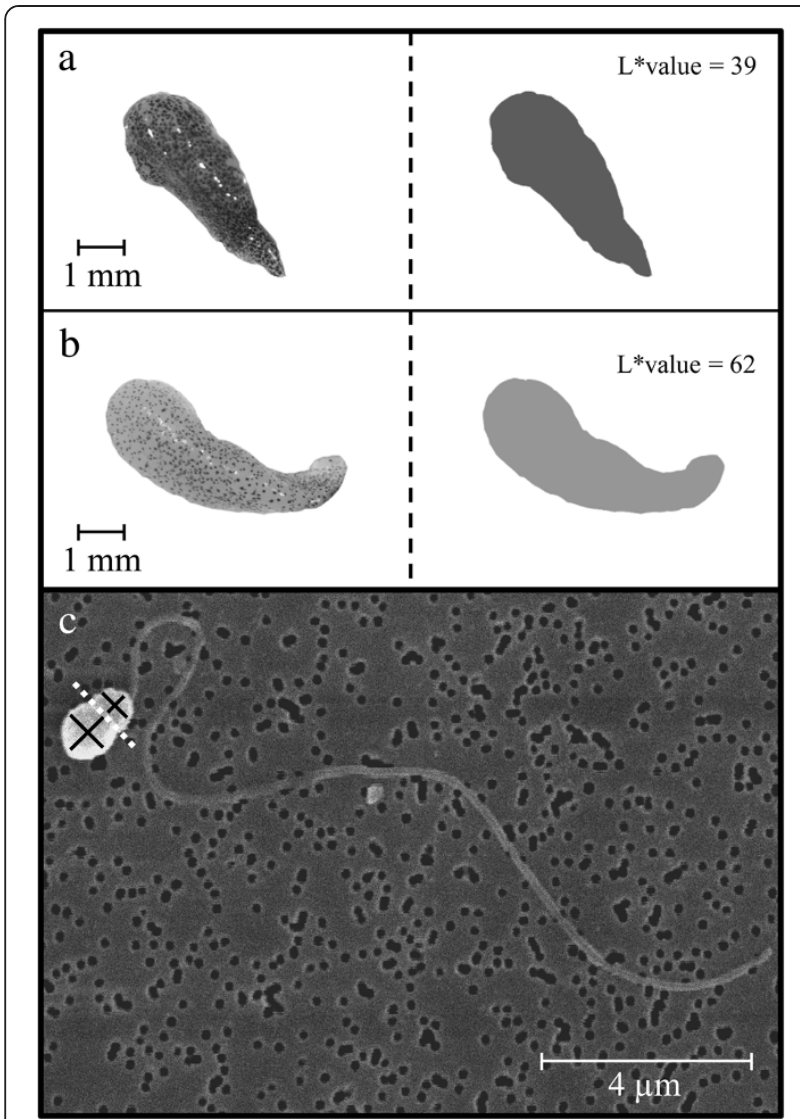

Figure 2 Representative testes and sperm of three-spined stickleback males. Testis of a young (a) and an old (b) male and on the right side the corresponding $L^{*}$ value for testis brightness as a measure of testis melanisation (see Mehlis et al. 2012). (c) Sperm head, mid-piece, and tail can be distinguished on the SEM image. The black lines indicate head length and width as well as mid-piece length and width, the dotted white line indicates the boundary between head and mid-piece.

2010). However, this topic is controversial (see Snook 2005 for an overview) and many studies found no relationship between sperm morphology traits and sperm swimming performance (e.g. Gage et al. 2002; Locatello et al. 2007). Nevertheless, there is evidence that sperm motility is associated with mid-piece volume (Anderson and Dixson 2002) and the evolution of sperm mid-piece volume has been affected by selection pressures resulting from sperm competition (Anderson et al. 2005); the higher the mid-piece volume the higher the mitochondrial loading and thus flagellum beating frequency (Cardullo and Baltz 1991). The results of the present study show that sperm size and mid-piece volume were significantly larger in young males, suggesting higher quality sperm, as in sticklebacks fertilisation success is predicted by longer tail length, greater mid-piece volume and smaller head to tail length ratio (TCMB et al. unpublished data). Young and old males did however not differ significantly in head to flagellum length ratio, another proxy for sperm motility (Humphries et al. 2008), leaving this issue open for further investigations.

Sperm are known to be highly prone to oxidative stress (e.g. Aitken and Baker 2006). Helfenstein et al. (2010) reported the first experimental evidence that development of carotenoid-based ornaments and sperm quality may be linked through oxidative stress. Carotenoid-based conspicuous yellow, orange and red colour patterns are widespread in many vertebrate species (e.g. Hill et al. 2002). The colour variables for the stickleback cheek region that were measured in the present study indicate a stronger deposition of carotenoids in terms of a more chromatic and darker breeding coloration in younger males (Gomez et al. 2011) as an indicator of higher individual quality compared to older males. In sticklebacks, the intensity of the red/orange breeding coloration is one of the key determinants of female mate-choice decisions (e.g. McLennan and McPhail 1990; Bakker and Milinski 1993). If carotenoid availability is limited, these pigments will be traded off between fitness components such as sexual ornamentation and immunoresponsive capacities (Lozano 1994), thereby maintaining the honesty of carotenoid-based signals (e.g. Blount et al. 2003; but see Navara and Hill 2003). In the laboratory, both young and old males were fed Chironomus spec. larvae that contain a.o. lutein (Czeczuga 1970), a major carotenoid for the development of males' breeding coloration (Wedekind et al. 1998). Since animals cannot synthesise carotenoids de novo (Goodwin 1984), the given food supply was the only carotenoid source for the males. The less developed breeding coloration of older males might imply that old males' ability to cope with oxidative stress may be reduced, thus supporting the oxidative stress ageing theory as suggested by Harman (1956).

Testis melanisation occurs in many animal taxa, for example in fish (Louiz et al. 2009), amphibians (Zieri et al. 2007), reptiles (Guillette et al. 1983), birds (Galván et al. 2011), and mammals (Poole and Lawton 2009). In birds, for example, testicular melanisation has been evolved in species with high rates of accumulated mitochondrial mutations and has been supposed to be an adaptive response related to the protective capacity of melanin against oxidative stress (Galván et al. 2011). The current study showed that the testes of older stickleback males were less pigmented, indicating that younger males might be able to handle oxidative stress better than their older brothers (but see Andziak et al. 2006). At the same time younger males were less pigmented in the dorsal region. This may indicate a trade-off between the deposition of melanin pigments in skin and testis tissue. Such a correlation between the proportion of plumage coloured by melanin and occurrence of testicular melanisation has not been found in birds (Galván et al. 2011). However, the precise function and relevance of 
testis melanisation in sticklebacks is unknown and requires further investigation.

Older males were significantly larger and heavier than their younger brothers. This is not surprising due to the fact that fish have indeterminate growth and also in sticklebacks age is largely confounded with body size (Allen and Wootton 1982). Furthermore, in three-spined sticklebacks, larger males are more aggressive (Mehlis et al. 2010), have an advantage in dominance fights (Rowland 1989), and females find larger males more attractive possibly due to their higher paternal quality and/or territorial quality (Kraak et al. 1999). However, females also prefer more intensely red-coloured stickleback males (Bakker and Milinski 1993; Kraak et al. 1999; Künzler and Bakker 2001) and the results of the present study show that the relative area of red breeding coloration was greater in large males. It remains unclear how the attractiveness in terms of breeding coloration (higher saturated coloration and hue in the red/orange spectral region in young males but greater area of red breeding coloration in large old males) is traded off against body size, and thus whether younger males have the edge over their older brothers.

\section{Conclusions}

To conclude, the results revealed that advanced age can have beneficial as well as detrimental effects on an individual male stickleback's reproductive traits. Older males were larger (dominance advantage) and had more sperm than their younger brothers. They might be, however, at a disadvantage in terms of mate acquisition (less intense nuptial signal) and fertilisation ability (lower quality sperm). The less developed nuptial colour, testis melanisation and sperm quality could be the result of oxidative stress to cells and tissues accumulating over time (Harman 1956). However, one has to mention that further investigations are needed to confirm that the results of this explanatory study are really important under natural conditions, especially when stickleback males are confronted with sperm competition and whether this influences males' fertilisation abilities and reproductive success. Furthermore, given the damaging effects of progressive ageing, it is interesting to note that most males from the study population do not live long enough to reach a second reproductive phase in the field. Taken together, these observations support ultimate ageing theories suggesting that an age-related decrease in fitness might select for an increased reproductive investment early in life (Medawar 1952; Williams 1957).

\section{Methods}

\section{Experimental subjects}

About 500 three-spined sticklebacks from an anadromous, genetically heterogeneous population (Heckel et al. 2002) were caught during their spring migration in April 2008 on the island of Texel, the Netherlands. Sticklebacks were purchased from a commercial fisherman, who has the permission to catch the fish. Within 5-6 hours fish were transported in large boxes (half filled with sea- and tapwater) to the Institute for Evolutionary Biology and Ecology in Bonn, Germany, where they were kept together in a large outside-tank (750 l), with air ventilation and a constant supply of tap-water at a flow rate of $31 \mathrm{~min}^{-1}$ and fed with red mosquito larvae (Chironomus spec.). The probability that individuals from the used study population die after their first breeding season seems to be high due to two reasons. First, the frequency distribution of standard lengths of the sampled fish during spring migration was single-peaked (MM personal observation). Second, a previous study did not find any large individuals during autumn migration from the breeding sites to the sea (van Mullem and van der Vlugt 1964). Nevertheless, under laboratory conditions it is common that these fish live 30 months or even longer and still reproduce (e.g. Mehlis et al. 2008; Mehlis et al. 2012).

To achieve different family groups, a randomly chosen male was allowed to spawn with a randomly chosen female, which were transferred to the laboratory with simulated summer conditions (day length $16 \mathrm{~L}: 8 \mathrm{D}$, temperature $17 \pm 1^{\circ} \mathrm{C}$ ) for reproduction; thereby 40 clutches were produced in June 2008. Parents were only used once to avoid pseudoreplication. Thus, males used in this study originated from the F1 generation of randomly crossed wild-caught sticklebacks. To exclude paternal effects clutches were removed from the males' tanks $2 \mathrm{~h}$ after fertilisation and split into two full-sib groups. Hatched fry were fed daily with Artemia nauplii during the first month of age and juveniles/adults were fed with red mosquito larvae (Chironomus spec.) in excess later on. At an age of three weeks group size was reduced to 50 individuals, which were kept in holding tanks measuring $30 \mathrm{~cm} \times 20$ $\mathrm{cm} \times 20 \mathrm{~cm}$ (length $\times$ width $\times$ height). Twenty weeks later, fish were transferred to holding tanks measuring $50 \mathrm{~cm} \times$ $30 \mathrm{~cm} \times 30 \mathrm{~cm}$. Groups that consisted of more than $20 \mathrm{in}-$ dividuals were split again (eleven groups originating from eight families) and families that consisted of fewer than 20 individuals were fused again (15 families). At this time point all holding tanks were placed in an air-conditioned room under standardised winter light-regime (8L:16D, 17 $\pm 1^{\circ} \mathrm{C}$ ). In sticklebacks, sexual maturation is stimulated by long photoperiods (Borg et al. 2004). Hence, to start the breeding season the light regime was changed to summer conditions in May 2009 (16L:8D, $17 \pm 1^{\circ} \mathrm{C}$ ), which lasted five months and followed by a second simulated winter period. At an age of 20 months fish were put under summer conditions again.

During both simulated breeding seasons randomly chosen males that showed signs of nuptial coloration in 
their holding tanks were individually isolated in separate tanks $(30 \mathrm{~cm} \times 20 \mathrm{~cm} \times 20 \mathrm{~cm})$ for nest building. It was ensured that all males used were virgin, because they had no possibility to build a nest in their holding tank and they were not paired to any female in their nesting tank. Collecting data such as total testis mass and sperm count (see below) is invasive; hence it was not possible to measure these traits for one male through time. In addition, only males that had built a nest were used, which ensures that they were reproductively active. In total, 161 males originating from 32 families built a nest. This included 60 males from 32 families, which were allowed to build nests in their first summer "young males") and 101 males from 22 families, which were not allowed to build nests until the following summer ("old males"). During both simulated breeding seasons, data collection for young and old males followed the same pattern, which is subsequently explained in detail.

\section{Measurement of body traits}

Males' body size (S) and mass $(\mathrm{M})$ were determined and afterwards their body condition (BC) was calculated following Bolger and Connolly $\left(1989 ; \mathrm{BC}=100 * \mathrm{M} / \mathrm{S}^{3}\right)$. Body measures were taken before isolating the males and shortly before euthanising them (see below). Hence, for each male both values were averaged for further analyses.

\section{Measurement of breeding coloration}

To determine the red area of male breeding coloration standardised digital still photographs were taken inside a black photo box using a camera (Nikon D70s with a Nikkor micro lens) connected to two flashes (Metz 20 BC6). This is a method frequently used in sticklebacks (e.g. Bakker and Mundwiler 1994; Frommen et al. 2008). A black curtain was tightened around the photo box to prevent any stray light from entering the box.

Males that had a nest for two days were stimulated with a receptive female (swollen abdomen filled with eggs) for $15 \mathrm{~min}$. Afterwards, the male was put into a transparent plastic box $(9.5 \mathrm{~cm} \times 7 \mathrm{~cm} \times 7 \mathrm{~cm})$ containing some water and the left lateral side, visible through high quality glass (Hoya HMC UV filter), was photographed with an exposure time of 1/125 $\mathrm{s}$ and focal aperture of 16. Images were processed using Adobe Photoshop CS4. A white Munsell card (N10) visible on each picture served as white balance. The shape of the fish head (from snout to gills) was marked using the magnetic-lasso-tool and subsequently saved on a white background $(1400 \times 1000$ pixel $)$. To finish the quantification of the red area, images of the fish head were uploaded in Sigma Scan Pro 5.0 and the percentage of red area (threshold hue: 0-40; threshold saturation: 20-100) was determined in relation to the total area of the fish head and the white background.
The expression of male breeding coloration was quantified by using reflectance measurements of the skin, which were taken on average two days after the photograph (median and quartiles: 2, 2, 4). Shortly before reflectance measurements, males were stimulated with a receptive female for $15 \mathrm{~min}$. Reflectance scans were taken with a spectrophotometer (Avantes AVS-USB2000) connected to a deuterium-halogen light source (Avantes DH-2000) for illumination (see Rick et al. 2011 for a detailed description). Measurements were made directly below the eye (A-region, breeding coloration) and at the dorsum below the first dorsal spine (R-region). Data were recorded without changing probe contact using Spectrawin 5.1 (Avantes) and imported into Microsoft Excel. About twenty measurements were taken in succession and averaged for the A-region (median and quartiles: 20, 17, 27) and the R-region (median and quartiles: 18, 16, 19).

The reflectance spectrum of the carotenoid-based breeding coloration of three-spined stickleback males is double-peaked with one peak in the UV-region and an extended plateau at longer wavelengths (Rick and Bakker 2008; Figure 1). Hence, for the A-region the UV chroma $\left(\mathrm{C}_{\mathrm{UV}}=\mathrm{R}_{300-400} / \mathrm{R}_{300-700} ; \mathrm{R}=\right.$ reflectance at $\mathrm{a}$ given wavelength) and, as a measure of carotenoid pigmentation (e.g. Blount and Pike 2012), carotenoid chroma $\left(C_{\text {caro }}=\left(R_{700}-R_{450}\right) / R_{700}\right)$ were calculated. The $R_{50}$ value for the A-region was determined, defined as the wavelength at the halfway reflectance point between the minimum reflectance (400 to $500 \mathrm{~nm}$ ) and the maximum reflectance (500 to $700 \mathrm{~nm}$ ). Higher $R_{50}$ values indicate a more red-shifted hue of the measured region (Rick and Bakker 2008; Pike et al. 2011). Finally, the total brightness $\left(R_{300-700}\right)$ was measured for both regions.

\section{Measurement of testis traits}

Directly after reflectance measurements were taken, males were euthanised quickly by decapitation, both testes were removed, placed separately on a tissue paper and weighed to the nearest milligram (OHAUS, Explorer, E11140) so that the relative testis mass (gonadosomatic index, GSI,) could be calculated after de Vlaming et al. (1982; GSI = $\left(\mathrm{TM}_{\text {total }} / \mathrm{M}\right) * 100$, where $\mathrm{TM}_{\text {total }}$ is the sum of the absolute mass of both testes).

As the testes of three-spined stickleback males are covered with melanophores and there is striking betweenmale variation in testicular melanisation and the $L$ *value (brightness) is a good indicator of melanophore density (see Figure 2a-b; Mehlis et al. 2012), the intensity of melanophore pigmentation was quantified using the same method as described in Mehlis et al. (2012). Melanophores are generally thought to protect the testes from deleterious UV light due to their strong light absorbance (Kaidbey et al. 1979; Plonka et al. 2009) and/or to protect 
males' germ cells from oxidative stress (Galván et al. 2011). Testis brightness was determined for each male's testis $\left(\mathrm{L}^{*}\right.$ left and $\mathrm{L}^{*}$ right $)$ and finally averaged $\left(\mathrm{L}^{*}\right.$ total $)$.

\section{Measurements of sperm traits}

The measurement of sperm number was solely conducted on the left testis because sperm number of left and right testes are highly correlated in sticklebacks (Bakker et al. 2006). Right testes were used for later SEM-preparation (see below) hence they were stored in an Eppendorf tube containing $500 \mu \mathrm{l} 4 \%$ formalin. The left testis was pestled in $200 \mu \mathrm{l}$ of a non-activating medium (for mixture see Fauvel et al. 1999). Ten microlitres of the sperm suspension were diluted in $190 \mu \mathrm{l}$ of tap water in order to reduce sperm density. Twelve microlitres of this dilution were filled into an improved Neubauer counting chamber (Labor Optik, $0.0025 \mathrm{~mm}^{2}$, depth $0.1 \mathrm{~mm}$ ). Sperm were counted in 32 equally distributed cells and averaged, so that the total number of sperm was calculated (see Mehlis et al. 2012).

Sperm morphology was determined by scanning electron microscopy (SEM; Figure 2c). The preparation of sperm followed Mortimer (1994) and was adapted for sticklebacks providing highly repeatable measurements of sperm traits (see Mehlis et al. 2012). Sperm variables were measured using 3000-6000 magnified SEM-images (Leitz AMR 1000), which were digitised using DISS (Digital Image Scanning System, Point Electronic GmbH, Halle, Germany) and DIPS (Digital Image Processing System V 2.5.2.1, Point Electronic GmbH, Halle, Germany). Sperm morphology variables (head length (hl), head width (hw), mid-piece length $(\mathrm{ml})$, mid-piece width $(\mathrm{mw})$ and tail length (tl)) were measured only on images that showed intact sperm (with a well visible head and a complete tail; see Figure 2c) using ImageJ. On average 20 sperm were measured per male (median and quartiles: 20, 19, 22).

Unfortunately, it was not possible to measure sperm motility directly because after dissection testes were stored in $4 \%$ formalin. However, in stickleback's fertilisation success is predicted by tail length, mid-piece volume and head to tail length ratio (TCMB et al. unpublished data). Thus, the head to tail length ratio $((\mathrm{hl}+\mathrm{ml}) / \mathrm{tl})$ and mid-piece volume $\left(\pi *(\mathrm{mw} / 2)^{2} * \mathrm{ml}\right)$ were calculated as a proxy of sperm motility being an indicator of sperm quality.

\section{Competing interests}

The authors declare that no competing interests exist.

\section{Authors' contributions}

MM and TCMB conceived and designed the study and wrote the paper. MM performed the experiments and analyzed the data. Both authors read and approved the final manuscript.

\section{Acknowledgements}

We are grateful to the "Bakker" research-group, especially Ingolf P. Rick and Meike Hiermes, for discussion. We thank Jan Hottentot for catching the sticklebacks. Lukas K. Hilke is acknowledged for help with the determination of testis melanisation and Dagmar Wenzel for help in measuring SEM images. Deborah A. McLennan is also kindly acknowledged for language corrections. This research was funded by the Deutsche

Forschungsgemeinschaft (DFG) (BA 2885/4-1).

Received: 25 January 2013 Accepted: 4 April 2013

Published: 20 April 2013

\section{References}

Aitken RJ, Baker M (2006) Oxidative stress, sperm survival and fertility control. Mol Cell Endocrinol 250:66-69

Allen JRM, Wootton RJ (1982) Age, growth and rate of food consumption in an upland population of the three-spined stickleback, Gasterosteus aculeatus L. J Fish Biol 21:95-105

Anderson MJ, Dixson AF (2002) Sperm competition: motility and the midpiece in primates. Nature 416:496-496

Anderson MJ, Nyholt J, Dixson AF (2005) Sperm competition and the evolution of sperm midpiece volume in mammals. J Zool 267:135-142

Andziak B, O'Connor TP, Qi W, DeWaal EM, Pierce A, Chaudhuri AR, Van Remmen $H$, Buffenstein R (2006) High oxidative damage levels in the longest-living rodent, the naked mole-rat. Aging Cell 5:463-71

Bakker TCM, Milinski M (1993) The advantages of being red: sexual selection in the stickleback. Mar Behav Physiol 23:287-300

Bakker TCM, Mundwiler B (1994) Female mate choice and male red coloration in a natural three-spined stickleback (Gasterosteus aculeatus) population. Behav Ecol 5:74-80

Bakker TCM, Zbinden M, Frommen JG, Weiss A, Largiadèr CR (2006) Slow fertilization of stickleback eggs: the result of sexual conflict? BMC Ecol 6:7

Balbontín J, de Lope F, Hermosell IG, Mousseau TA, Møller AP (2011) Determinants of age-dependent change in a secondary sexual character. J Evol Biol 24:440-448

Beck CW, Promislow DEL (2007) Evolution of female preference for younger males. PLoS One 2:e939

Billard R, Takashima F (1983) Resorption of spermatozoa in the sperm duct of rainbow trout during the post-spawning period. B Jpn Soc Sci Fish 49:387-392

Blount J, Pike TW (2012) Deleterious effects of light exposure on immunity and sexual coloration in birds. Funct Ecol 26:37-45

Blount JD, Metcalfe NB, Birkhead TR, Surai PF (2003) Carotenoid modulation of immune function and sexual attractiveness in zebra finches. Science 300:125-127

Bolger T, Connolly PL (1989) The selection of suitable indices for the measurement and analysis of fish condition. J Fish Biol 34:171-182

Borg B (1982) Seasonal effects of photoperiod and temperature on spermatogenesis and male secondary sexual characters in the three-spined stickleback, Gasterosteus aculeatus. Can J Zool 60:3377-3386

Borg B, Bornestaf C, Hellqvist A, Schmitz M, Mayer I (2004) Mechanisms in the photoperiodic control of reproduction in the stickleback. Behaviour 141:1521-1530

Candolin U, Vlieger L (2013) Should attractive males sneak: the trade-off between current and future offspring. PLoS One 8:e57992

Cardullo RA, Baltz JM (1991) Metabolic regulation in mammalian sperm: mitochondrial volume determines sperm length and flagellar beat frequency. Cell Motil Cytoskelet 19:180-188

Cubillos ER, Guderley HE (2000) Analysis of the factors related with mate choice and reproductive success in male three-spined sticklebacks. J Fish Biol 56:1201-1216

Czeczuga B (1970) Some carotenoids in Chironomus annularius Meig. larvae (Diptera: Chironomidae). Hydrobiologia 36:353-360

de Vlaming V, Grossman GD, Chapman F (1982) On the use of the gonosomatic index. Comp Biochem Physiol 73:31-39

Dean R, Cornwallis CK, Lovlie H, Worley K, Richardson DS, Pizzari T (2010) Male reproductive senescence causes potential for sexual conflict over mating. Curr Biol 20:1192-1196

DuVal EH (2012) Variation in annual and lifetime reproductive success of lancetailed manakins: alpha experience mitigates effects of senescence on siring success. Proc R Soc Lond B 279:1551-1559

Fauvel C, Savoye O, Dreanno C, Cosson J, Suquet M (1999) Characteristics of sperm of captive seabass in relation to its fertilization potential. J Fish Biol 54:356-369

Fitzpatrick JL, Garcia-Gonzalez F, Evans JP (2010) Linking sperm length and velocity: the importance of intramale variation. Biol Lett 6:797-799 
Frommen JG, Luz C, Mazzi D, Bakker TCM (2008) Inbreeding depression affects fertilization success and survival but not breeding coloration in threespine sticklebacks. Behaviour 145:425-441

Gage MJG, MacFarlane C, Yeates S, Shackleton R, Parker GA (2002) Relationships between sperm morphometry and sperm motility in the Atlantic salmon. J Fish Biol 61:1528-1539

Galván I, Møller AP, Erritzøe J (2011) Testicular melanization has evolved in birds with high mtDNA mutation rates. J Evol Biol 24:988-998

Gambling SJ, Reimchen TE (2012) Prolonged life span among endemic Gasterosteus populations. Can J Zool 90:284-290

Garratt M, Stockley P, Armstrong SD, Beynon RJ, Hurst JL (2011) The scent of senescence: sexual signalling and female preference in house mice. J Evol Biol 24:2398-2409

Gasparini C, Marino IAM, Boschetto C, Pilastro A (2010) Effect of male age on sperm traits and sperm competition success in the guppy (Poecilia reticulata). J Evol Biol 23:124-135

Goldschmidt T, Foster SA, Sevenster P (1992) Inter-nest distance and sneaking in the three-spined stickleback. Anim Behav 44:793-795

Gomendio M, Roldan ERS (1991) Sperm competition influences sperm size in mammals. Proc R Soc Lond B 243:181-185

Gomendio M, Roldan ERS (2008) Implications of diversity in sperm size and function for sperm competition and fertility. Int J Dev Biol 52:439-447

Gomez D, Thery M, Gauthier A-L, Lengagne T (2011) Costly help of audiovisual bimodality for female mate choice in a nocturnal anuran (Hyla arborea). Behav Ecol 22:889-898

Goodwin TW (1984) The Biochemistry of the Carotenoids, vol 2. Animals, Chapman \& Hall, London

Guillette L, Weigel J, Flater G (1983) Unilateral testicular pigmentation in the Mexican lizard Sceloporus variabilis. Copeia 1983:155-161

Harcourt AH, Harvey PH, Larson SG, Short RV (1981) Testis weight, body weight and breeding system in primates. Nature 293:55-57

Harman D (1956) Aging: a theory based on free radical and radiation chemistry. J Gerontol 11:298-300

Heckel G, Zbinden M, Mazzi D, Kohler A, Reckeweg G, Bakker TCM, Largiadèr CR (2002) Microsatellite markers for the three-spined stickleback (Gasterosteus aculeatus L.) and their applicability in a freshwater and an anadromous population. Conserv Genet 3:79-81

Helfenstein F, Losdat S, Møller AP, Blount JD, Richner H (2010) Sperm of colourful males are better protected against oxidative stress. Ecol Lett $13: 213-222$

Hill GE, Inouye CY, Montgomerie R (2002) Dietary carotenoids predict plumage coloration in wild house finches. Proc R Soc Lond B 269:1119-1124

Hoffmann E, Walstad A, Karlsson J, Olsson P-E, Borg B (2012) Androgen receptor beta mRNA levels in different tissues in breeding and post-breeding male and female sticklebacks, Gasterosteus aculeatus. Reprod Biol Endocrinol 10:23

Holliday R (2006) Aging is no longer an unsolved problem in biology. Ann N Y Acad Sci 1067:1-9

Hughes KA, Reynolds RM (2005) Evolutionary and mechanistic theories of aging. Annu Rev Entomol 50:421-445

Humphries S, Evans JP, Simmons LW (2008) Sperm competition: linking form to function. BMC Evol Biol 8:319

Jamieson IG, Colgan PW (1992) Sneak spawning and egg stealing by male threespine sticklebacks. Can J Zool 70:963-967

Johnson SL, Gemmel NJ (2012) Are old males still good males and can females tell the difference? BioEssays 34:609-619

Kaidbey K, Agin P, Sayre R, Kligman A (1979) Photoprotection by melanin - a comparison of black and Caucasian skin. J Amer Acad Dermatol 1:249-260

Kanuga MK, Benner MJ, Doble JA, Wilson Leedy JG, Robison BD, Ingermann RL (2011) Effect of aging on male reproduction in zebrafish (Danio rerio). J Exp Zool 315:156-161

Kraak SBM, Bakker TCM, Mundwiler B (1999) Sexual selection in sticklebacks in the field: correlates of reproductive, mating, and paternal success. Behav Ecol 10:696-706

Künzler R, Bakker TCM (2001) Female preference for single and combined traits in computer animated stickleback males. Behav Ecol 12:681-685

Largiadèr CR, Fries V, Bakker TCM (2001) Genetic analysis of sneaking and egg thievery in a natural population of the three-spined stickleback (Gasterosteus aculeatus L.). Heredity 86:459-468

Locatello L, Pilastro A, Deana R, Zarpellon A, Rasotto MB (2007) Variation pattern of sperm quality traits in two gobies with alternative mating tactics. Funct Ecol 21:975-981
Louiz I, Ben-Attia M, Ben-Hassine O (2009) Gonadosomatic index and gonad histopathology of Gobius niger (Gobiidea, Teleost) from Bizerta lagoon (Tunisia): evidence of reproduction disturbance. Fish Res 100:266-273

Lozano GA (1994) Carotenoids, parasites, and sexual selection. Oikos 70:309-311

McLennan DA, McPhail JD (1990) Experimental investigations of the evolutionary significance of sexually dimorphic nuptial colouration in Gasterosteus aculeatus (L.): the relationship between male colour and female behaviour. Can J Zool 68:482-492

Medawar PB (1952) An Unsolved Problem of Biology. H.K. Lewis \& Co, London

Medvedev ZA (1990) An attempt at a rational classification of theories of ageing. Biol Rev 65:375-398

Mehlis M, Bakker TCM, Frommen JG (2008) Smells like sib spirit: kin recognition in three-spined sticklebacks (Gasterosteus aculeatus) is mediated by olfactory cues. Anim Cogn 11:643-650

Mehlis M, Bakker TCM, Engqvist L, Frommen JG (2010) To eat or not to eat: eggbased assessment of paternity triggers fine-tuned decisions about filial cannibalism. Proc R Soc Lond B 277:2627-2635

Mehlis M, Frommen JG, Rahn AK, Bakker TCM (2012) Inbreeding in sticklebacks (Gasterosteus aculeatus L.): effects on testis and sperm traits. Biol J Linn Soc 107:510-520

Milewski LAK (2010) The evolution of ageing. Bioscience Horizons 3:77-84

Mortimer D (1994) Preparation of human spermatozoa for electron microscopy. In: Mortimer D (ed) Practical Laboratory Andrology. Oxford University Press, Oxford, pp 168-173

Navara KJ, Hill GE (2003) Dietary carotenoid pigments and immune function in a songbird with extensive carotenoid-based plumage coloration. Behav Ecol 14:909-916

Parker GA (1982) Why are there so many tiny sperm? Sperm competition and the maintenance of two sexes. J Theor Biol 96:281-294

Parker GA (1990) Sperm competition games: raffles and roles. Proc R Soc Lond B 242:120-126

Pike TW, Bjerkeng B, Blount JB, Lindstroem J, Metcalfe NB (2011) How integument colour reflects its carotenoid content: a stickleback's perspective. Funct Ecol 25:297-304

Pitcher TE, Rodd FH, Rowe L (2007) Sexual colouration and sperm traits in guppies. J Fish Biol 70:165-177

Plonka P, Passeron T, Brenner M, Tobin D, Shibahara S, Thomas A (2009) What are melanocytes really doing all day long...? Exp Dermatol 18:799-819

Poole A, Lawton C (2009) The translocation and post release settlement of red squirrels Sciurus vulgaris to a previously uninhabited woodland. Biodivers Conserv 18:3205-3218

Raveh S, Heg D, Dobson FS, Coltman D, Gorrell J (2010) Mating order and reproductive success in male Columbian ground squirrels (Urocitellus columbianus). Behav Ecol 21:537-547

Rick IP, Bakker TCM (2008) Males do not see only red: UV wavelengths and male territorial aggression in the three-spined stickleback (Gasterosteus aculeatus). Naturwissenschaften 95:631-638

Rick IP, Mehlis M, Bakker TCM (2011) Male red ornamentation is associated with female red sensitivity in sticklebacks. PLoS One 6:e25554

Rico C, Kuhnlein U, FitzGerald GJ (1992) Male reproductive tactics in the threespine stickleback - an evaluation by DNA fingerprinting. Mol Ecol 1:79-87

Rose MR, Burke MK, Shahrestani P, Mueller LD (2008) Evolution of ageing since Darwin. J Genet 87:363-371

Rowe M, Pruett-Jones S (2011) Sperm competition selects for sperm quantity and quality in the Australien maluridae. PLoS One 6:e15720

Rowland WJ (1989) The effects of body size, aggression and nuptial coloration on competition for territories in male threespine sticklebacks, Gasterosteus aculeatus. Anim Behav 37:282-289

Sasson DA, Johnson SL, Brockmann HJ (2012) The role of age on sperm traits in the American horseshoe crab, Limulus polyphemus. Anim Behav 84:975-981

Schneider L (1969) Experimentelle Untersuchungen über den Einfluß von Tageslänge und Temperatur auf die Gonadenreifung beim Dreistachligen Stichling (Gasterosteus aculeatus). Oecologia 3:249-265

Snook RR (2005) Sperm in competition: not playing by the numbers. Trends Ecol Evol 20:46-53

Somashekar K, Krishna MS (2011) Evidence of female preference for older males in Drosophila bipectinata. Zool Stud 50:1-15

Stockley P, Gage MJG, Parker GA, Møller AP (1997) Sperm competition in fishes: the evolution of testis size and ejaculate characteristics. Am Nat 149:933-954 
Symonds MRE, Moussalli A (2011) A brief guide to model selection, multimodel inference and model averaging in behavioural ecology using Akaike's information criterion. Behav Ecol Sociobiol 65:13-21

van Mullem PJ, van der Vlugt JC (1964) On the age, growth and migration of the anadromous stickleback Gasterosteus aculeatus L. investigated in mixed populations. Arch Néerl Zool 16:111-139

Velando A, Noguera JC, Drummond H, Torres R (2011) Senescent males carry premutagenic lesions in sperm. J Evol Biol 24:693-697

Verburgt L, Ferreira M, Ferguson JWH (2011) Male field cricket song reflects age, allowing females to prefer young males. Anim Behav 81:19-29

Vlieger L, Candolin U (2009) How not to be seen: does eutrophication influence three-spined stickleback Gasterosteus aculeatus sneaking behaviour? J Fish Biol 75:2163-2174

Wedekind C, Meyer P, Frischknecht M, Niggli UA, Pfander H (1998) Different carotenoids and potential information content of red coloration of male three-spined stickleback. J Chem Ecol 24:787-801

Williams GC (1957) Pleiotropy, natural selection, and the evolution of senescence. Evolution 11:398-411

Wootton RJ (1976) The Biology of the Sticklebacks. Academic Press, London

Yang H, Chryssikos T, Houseni M, Alzeair S, Sansovini M, Iruvuri S, Torigian D, Zhuang H, Dadparvar S, Basu S, Alavi A (2011) The effects of aging on testicular volume and glucose metabolism: an investigation with ultrasonography and FDG-PET. Mol Imag Biol 13:391-398

Zbinden M, Largiadèr CR, Bakker TCM (2001) Sperm allocation in the threespined stickleback. J Fish Biol 59:1287-1297

Zbinden M, Mazzi D, Künzler R, Largiadèr CR, Bakker TCM (2003) Courting virtual rivals increase ejaculate size in sticklebacks (Gasterosteus aculeatus). Behav Ecol Sociobiol 54:205-209

Zbinden M, Largiadèr CR, Bakker TCM (2004) Body size of virtual rivals affects ejaculate size in sticklebacks. Behav Ecol 15:137-140

Zieri R, Taboga SR, de Oliveira C (2007) Melanocytes in the testes of Eupemphix nattereri (Anura, Leiuperidae): histological, stereological, and ultrastructural aspects. Anat Rec 290:795-800

doi:10.1186/2193-1801-2-175

Cite this article as: Mehlis and Bakker: Male reproductive traits of fullsibs of different age classes in three-spined sticklebacks (Gasterosteus aculeatus). SpringerPlus 2013 2:175.

\section{Submit your manuscript to a SpringerOpen ${ }^{\circ}$ journal and benefit from:}

- Convenient online submission

- Rigorous peer review

- Immediate publication on acceptance

- Open access: articles freely available online

- High visibility within the field

- Retaining the copyright to your article

Submit your next manuscript at $\gg$ springeropen.com 